\title{
Gobierno local, agencia y Estado en el rediseño de la representación por la vía de la reelección consecutiva*
}

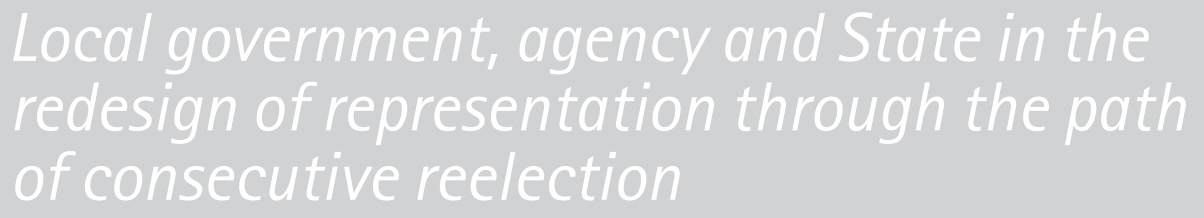

\section{José Luis Estrada Rodríguez*** Angélica Mendieta Ramírez ***}

\begin{abstract}
RESUMEN
La democracia se construye a partir de dos elementos: a partir de las instituciones que salvaguardan los derechos, por medio de la ley; y los ciudadanos que asumen un papel activo en la vigilancia de sus prerrogativas. Este trabajo realiza un análisis sobre los condicionantes de la reelección consecutiva a nivel municipal, recién aprobada en la reforma politico-electoral en 2014 Este fue un mecanismo para garantizar la agencia, en términos de O'Donell, caracterizada como la posibilidad de los ciudadanos de incidir en la representación política para promover la calidad democrática. La metodología utilizada es el análisis interpretativo de los autores y sus postulados, así como la exposición de sus argumentos. Se advierte que es necesario un rediseño institucional para modificar la relación existente entre el Estado y los ciudadanos en su capacidad de agentes politicos
\end{abstract}

PALABRAS CLAVE

Democracia, reelección, ciudadanos, Estado.

\begin{abstract}
Democracy is built on two elements: from the Institutions that Safeguard Rights, through the law; and citizens who take an active role in monitoring their prerogatives. This work makes an analysis on the conditions of Consecutive re-election at Municipal level, recently approved in the Political-electoral Reform in 2014. This was a mechanism to guarantee the agency, in terms of O'Donell, characterized as the possibility of citizens to influence political representation, to promote democratic quality. The methodology used is the interpretative analysis of the authors and their postulates, as well as the presentation of their arguments. It is noted that an institutional redesign is necessary to modify the relationship between the State and citizens in their capacity as political agents.
\end{abstract}

\section{KEYWORDS}

Democracy, reelection, citizens, State.

*Artículo recibido el 29 de julio de 2017 y aceptado para su publicación el 4 de diciembre de 2017

** Profesor Investigador Benemérita Universidad Autónoma de Puebla, México (luisholly@yahoo.com.mx) orcid: 0000-0003-0088-2157

*** Profesora Investigadora de la Facultad de Ciencias de la Comunicación, Benemérita Universidad Autónoma de Puebla, México (angelicamendietaramirez@yahoo.com.mx) 0RCID: 0000-0001-9344-8653 
SUM ARIO

1. Introducción

2. Hacia el nuevo orden político municipal

3. Inconsistencias del gobierno municipal

4. Modificaciones sustanciales para garantizar la agencia

5. Puntos concluyentes

\section{INTRODUCCIÓN}

El papel de los ciudadanos en la democracia es un punto que suscita polémica y discusión, porque los partidos políticos han tomado el papel de la representación política como un camino para el control y dominación sin contrapeso. En ese sentido, volver a la reelección consecutiva en México abre una pauta de interés para discutir y analizar cuáles son las posibilidades de promover un papel activo de los ciudadanos en torno a la democratización y gobernabilidad. Además, esto resulta relevante para analizar algunas de las variables que influyen en la calidad de la democracia.

Tomaremos para este análisis a un prolífico politólogo: Guillermo 0'Donnell. ${ }^{1}$ Lo anterior por sus aportaciones sobre la agencia, ese mecanismo que poseen los ciudadanos en una democracia para vigilar, controlar y promover un buen gobierno por la vía de los representantes. Hasta antes de la reforma institucional, no existía esa posibilidad de generar un diálogo con los gobernantes; por la falta de reelección en México. Estaba vetada esa posibilidad de incidencia real como contrapeso de poder, una de las principales características de un sistema consolidado de democracia. Los ciudadanos, como agentes, tienen derechos políticos y ciudadanos para elegir a sus representantes, pero también deben tenerlos para evaluar su trabajo, exigirles cuentas y evaluar sus resultados en las elecciones.

Al igual que 0'Donnell, la teoría del agente principal (TAP) está basada en los estudios realizados por James March y Johan P. Olson, quienes comenzaron a desarrollar sus ideas basados en el estudio de las organizaciones con el objetivo de explicar su conducta. ${ }^{2}$ Eugene Fama, economista y ganador del Premio Nobel de Economía en 2013, describe la delegación de funciones como un problema de oportunismo que sólo puede ser limitado a partir del control. Este

\footnotetext{
1 O'Donnell, Guillermo, Democracia, agencia y Estado. Teoría con intención comparativa, Buenos Aires, Prometeo, 2010, p. 9.

${ }^{2}$ Peters, Guy, El nuevo institucionalismo, teoria institucional en Ciencia Politica, Barcelona, Gedisa, 2003.
} 
ejercicio puede ser aplicado a los políticos, ya que sólo mediante la vigilancia de sus acciones es posible garantizar la eficiencia. ${ }^{3}$

Este nuevo institucionalismo normativo sostiene que los individuos no son individuos fragmentados, sino todo lo contrario, que forman parte de un amplio grupo organizacional y que actúan en conjunto para maximizar sus intereses y su beneficio personal, aunque también reflejan fuertemente los valores que acompañan las instituciones. La teoría del agente principal fue utilizada para estudiar la relación entre el dueño de una empresa (principal) y sus administradores (agente). Se encontró que existe una asimetría en la información de quien manda y de quien obedece, por lo cual existe oportunismo y cada actor tendrá intereses distintos y actuará con base en ellos. ${ }^{4}$

En ese sentido, la teoría plantea que es necesario erradicar este oportunismo, eliminando la distancia entre el principal y el agente; es decir, entre los ciudadanos y los políticos. Esto daría como resultado que ambos actores estarían en mejores condiciones; primordialmente, el principal podría monitorear al agente. No es fácil trasladar este procedimiento a la esfera política, por lo cual la teoría del agente principal requiere de mecanismos como la rendición de cuentas para asegurar que ambos actores actúan maximizando su utilidad y beneficio. La aplicación de esta teoría proviene de la observación reiterada de que el regulador dispone de información imperfecta respecto de las acciones emprendidas por el agente o respecto de las que debería emprender. ${ }^{5}$

El punto de partida está en reconocer a los ciudadanos como entes de poder capaces de controlar al gobierno con sus derechos y atribuciones. El ciudadano como agente es un aspecto crucial para entender la democracia, postula 0’Donnell; sobre dicho planteamiento se desarrollará este trabajo. La reelección en México plantea no sólo la posibilidad abierta de incidir en la política, porque la función principal del electorado es generar un gobierno que otorgue beneficios y cumpla con la visión contractual para la cual se constituye el Estado. No obstante, los mecanismos institucionales son determinantes, porque producen efectos sobre la manera en la cual se distribuye el poder. ${ }^{6}$ Incidir en un cambio democrático es posible sólo si se transforma el diseño institucional.

\footnotetext{
${ }^{3}$ Fama, Eugene, "Agency Problems and the Theory of the Firm", The Journal of Political Economy, vol. 88, núm. 2, pp. 288-307.

${ }^{4}$ Millán Valenzuela, Henio y Natal Martinez, Alejandro, La rendición de cuentas a la luz de la teoría agente-principal: un análisis de la democracia en México, México, El Colegio Mexiquense, 2006.

${ }^{5}$ Rivera Urrutia, Eugenio, "Teorías de la regulación en la perspectiva de las políticas públicas", Revista Gestión y política pública, vol. 13, núm. 2, p. 309.

${ }^{6}$ La reforma político-electoral fue aprobada en diciembre de 2013, entró en vigor el 10 de febrero de 201. Contempla la reelección del gobierno local, compuesto por el presidente municipal, sindicos y regidores; por un periodo adi-
} 
Asimismo, cuando hablamos del concepto de democracia, 0'Donnell se refiere al régimen político que Roberth Dahl denominó poliarquías, ${ }^{7}$ por sus múltiples acepciones de gobierno y representación política en el mundo. Para el caso latinoamericano, 0’Donnell elaboró un diagnóstico sobre la ausencia o débil reciprocidad entre gobierno y ciudadanos. Hay pocas posibilidades de influir en la toma de decisiones y participar en la vida pública.

José Sosa sostiene que existen pautas de evolución institucional que se han dado en los municipios de nuestro país producto de la globalización, industrialización y transformación demográfica. Pero dentro de estos cambios está una mayor apertura democrática y el reconocimiento de los derechos humanos y las garantías individuales; lo cual constituye uno de los resguardos más importantes de la ciudadanía: el poder ante los posibles abusos del Estado. ${ }^{8}$

Robin Hambleton y sus colaboradores ${ }^{9}$ comprobaron mediante una investigación que los gobiernos locales obtuvieron un mayor espacio democrático a partir de la globalización, en la década pasada, en Europa y Norteamérica. Sin embargo, quedaron maniatados por su dependencia económica al ámbito nacional, supeditados en la democracia incipiente que tenían. Por tanto, el municipio como estructura de gobierno requiere adaptarse para lograr un nuevo orden institucional a la altura de los retos, capaz de hacer frente a las necesidades imperiosas de crecimiento y desarrollo económico, principalmente; ya que, en México, por ejemplo, dicha entidad carece de sustentabilidad financiera. Esto produce centralismo. Sin embargo, para lograr este fin tiene inconsistencias políticas y administrativas que limitan su evolución.

El objetivo de este trabajo es examinar las inconsistencias institucionales del gobierno local en la esfera democrática, a partir de la aprobación de la reelección consecutiva nivel municipal, contemplada en la reforma político-electoral de 2014. ${ }^{10}$ Asimismo, se busca explicar cuál puede ser el papel de los agentes o ciudadanos en la construcción de un proceso de ciudadanía activa y representación democrática efectiva, con contrapeso y con diálogo permanente entre los agentes y el Estado.

cional de tres años. Empero, en tres estados (Coahuila, Veracruz e Hidalgo) el periodo es de cuatro años, por lo cual habrá de ajustar este criterio. Además, habrá que acotar que se otorga a cada estado de la república la potestad de decidir al respecto si van o no a la reelección y la particularidad que adquiera.

7 DahL, Robert, La poliarquía. Participación y oposición, Madrid, Tecnos, 1989.

${ }^{8}$ SoSA LóPEz, JoSÉ DE Jesús, "Gobiernos locales y desarrollo territorial en México", Frontera Norte, vol. 24, núm. 47.

${ }^{9}$ Hambleton, Robin, Sanvitch, Hank y Murray, Stewart, "Globalism and local democracy", en Robin Hambleton, Globalism and local democracy. Challenge and change in Europe and North America, New York, Palgrave - Macmillan, 2003.

${ }^{10}$ Celorio Juárez, Mariana, "La reforma político-electoral de 2014: avances, retrocesos y vacios", El Cotidiano, núm. 190, pp. 109-117. 
Asimismo, este documento de investigación se divide en tres apartados: el primero destaca la posibilidad de avanzar hacia un nuevo orden político municipal con la formación de la agencia, que 0’Donnell plantea como el rescate de las libertades y derechos. El segundo describe cuáles son las inconsistencias del municipio en torno a la democracia y sus imposibilidades bajo este régimen político institucionalizado. El tercer apartado propone modificaciones sustanciales para proveer una democracia de calidad y garantizar la agencia a partir de un rediseño institucional. De igual forma, una vez descritas y enumeradas las inconsistencias institucionales, este artículo propone establecer algunas estrategias para la transformación del paradigma del gobierno municipal (aprovechando la recién aprobada reelección de alcaldes) y abrir espacio a las reformas necesarias e impostergables para garantizar que los agentes o ciudadanos incidan de manera determinante en la democracia de nuestro país. Con la reforma político-electoral de 2014 se modificaron los artículos 59, 115 y 116 constitucionales, los cuales permitirán las reelección de senadores, diputados federales y locales; senadores, así como alcaldes, regidores y síndicos hasta por un periodo de 12 años.

La reelección permitirá romper con el esquema fundacional que limitaba la posibilidad de los agentes, para revocar o refrendar el poder de un gobierno en las elecciones de manera recurrente. En México, cada elección era única e irrepetible por los representantes de los partidos políticos que participaban en ellas. Con este breve diagnóstico basta. No se abunda en el tema por los innumerables trabajos que dan cuenta de estas afirmaciones (Fernando Dworak y colaboradores; Ixchel Pérez Durán, Gretchen González Parodi, Enrique Cabrero y David Arellano, entre otros).

Este trabajo describe estos fenómenos que hacen analizar estas inconsistencias, como relevantes y productivas para entender a la institución municipal. ${ }^{11}$ David Arellano coincide en que el municipio adolece de obsolescencia en sus estructuras institucionales de gobierno y administración, ausencia democrática, opacidad y debilidad institucional. ${ }^{12}$

\footnotetext{
11 Pérez Durán, Ixchel, "Efectos del diseño electoral municipal en la formación de poder", Gestión y política pública, vol. 17, núm. 2, pp. 381-423; González Parodi, Gretchen, Gobiernos municipales en México, México, uam; Cabrero Enrique y ARELLANO, DAVID, Los gobiernos municipales a debate. Un análisis de la institución municipal a través de la encuesta del INEGI, 2009, México, Centro de Investigación y Docencia Económica, 2011.

${ }^{12}$ Arellano, David, Cabrero Mendoza, Enrioue, Montiel Cuayatlayol Maria José y Aguilar Márouez, Israel, "Gobierno y administración pública municipal: un panorama de la fragilidad institucionalizada", en Enrique Cabrero y David Arellano, Los gobiernos municipales a debate. Un análisis de la institución municipal a través de la encuesta del INEGI, 2009, México, CIDE.
} 


\section{HACIA EL NUEVO ORDEN POLITICO MUNICIPAL}

Los municipios en México están investidos por un gobierno en apariencia cercano a la población y receptivo de las demandas ciudadanas. Los agentes, que son los políticos, no tienen un reconocimiento como promotores de la democracia. Los partidos políticos determinan quiénes serán los candidatos y, en los procesos sucesorios, quienes pueden contender por otro cargo de elección popular. Este puente roto entre representados y representantes es evidente con la falta de reelección. Como O'Donnell sostiene, la calidad de agente, consagrado en las constituciones de los países en América Latina, atribuyen al ciudadano no sólo la posibilidad de incidir en el proceso electoral, sino también en el reconocimiento de los derechos ligados a su carácter de representado.

En ese sentido, Joseph Colomer contemporáneo de O'Donnell, rescata sus contribuciones publicadas en el libro Transitions from Authoritarian Rule. Tentative Conclusions about Uncertain Democracies, sobre la transición a la democracia que tuvo América Latina, y el fuerte debilitamiento de las formas de control hacia los políticos. La tesis de O’Donnell, que denominó accountability horizontal (rendición de cuentas horizontal), se refiere a la existencia y funcionalidad de una red de agencias gubernamentales controladoras por los propios actos de gobierno, con el objetivo de prevenir y sancionar su conducta en caso de desviación. ${ }^{13}$

Volviendo al gobierno municipal, para centrar el análisis a este espacio de gobierno podemos decir que su estructura de poder está caracterizada por un cuerpo edilicio formado por un presidente municipal, uno o más síndicos y el número de regidores que determine la ley electoral. Desde la reforma constitucional de 1983, obtuvo el carácter de ser un orden de gobierno. Hasta antes sólo le correspondía administrar los servicios públicos.

Mauricio Merino sostiene que actualmente han logrado mayor autonomía los municipios, pero no se ha logrado la disputa en los espacios de decisión y el federalismo como orden de gobierno está incluso. ${ }^{14}$ Por ello, José María Ramos

260 e Ismael Aguilar Barajas describen a la institución municipal como débil, ausente del papel protagónico que debería tener en el desarrollo y consolidación de la democracia; porque sufren también de una visión cortoplacista y limitada

\footnotetext{
${ }^{13}$ Colomer, Joseph, "Democracy in Latin America: Minimalist in Concept and in Achievement". Latin American Research Review, vol. 52, núm. 3, pp. 505-512.

${ }^{14}$ Merino, Mauricio, "Nuevo federalismo, nuevos conflictos", Soledad Loaeza y Jean-François Prud'homme (coords), Los grandes problemas de México, XIV. Instituciones y procesos políticos, México, El Colegio de México, 2010.
} 
en sus capacidades por el cacicazgo, caudillaje, clientelismo, patrimonialismo; así como otros fenómenos contrarios a la calidad democrática. ${ }^{15}$

Este planteamiento coincide con los argumentos que esgrime Carlos Rodríguez, quien sostiene que el municipio es una pieza rezagada dentro del Estado mexicano, pero también rebasada por las exigencias y necesidades locales de los ciudadanos hacia la representación estatal que es el ayuntamiento. ${ }^{16}$ Por su parte, David Arellano y Enrique Cabrero concuerdan en que los riesgos de conservar estructuras débiles de gobierno local, administraciones precarias y falta de continuidad en las políticas públicas municipales ya tiene un alto costo para el país. ${ }^{17}$ Como muestra de ello, las capacidades para generar ingresos propios en nuestro país han llegado a un punto crítico. De los más de 2000 municipios, sólo 18 tienen vialidad financiera, es decir, pueden ser autosustentables; la otra gran mayoría dependen de las participaciones federales y los subsidios. ${ }^{18}$

Partimos de la siguiente hipótesis: la institución municipal en México está rebasada. No ha logrado realizar los cambios para garantizar el beneficio colectivo de los ciudadanos. Con la reelección consecutiva se podría modificar la representación política y la calidad democrática, al promover que cada uno de los agentes participe sustancialmente. Sobre este planteamiento, Samuel Huntington describió cuáles países funcionan y cuáles no, basado en el grado de orden institucional como garantía de éxito en la forma de gobernar y no en su forma de gobierno. Establece que las instituciones son determinantes y la inestabilidad gubernamental es producto del lento desarrollo en la estructura gubernamental. "El principal problema de la política es el atraso en el desarrollo de las instituciones políticas que deben respaldar los cambios económicos y sociales". ${ }^{19}$

Los municipios, desde este planteamiento, cada vez son más dinámicos y heterogéneos. En general, el panorama de los gobiernos locales es ampliamente complicado y diverso. Se han dado intentos para promover el nuevo orden institucional a través del nuevo federalismo, la descentralización, el impulso de la participación ciudadana y otros elementos que pueden definirse también

\footnotetext{
${ }^{15}$ Ramos José María e Ismael Aguilar Barajas, La gestión del desarrollo local en México: problemas y agenda, México, México, El Colegio de la Frontera Norte - Miguel Ángel Porrúa, 2009.

${ }^{16}$ Rodriguez Wallenius, Carlos, "La agenda ciudadana municipalista y la reforma del Estado", Política y Cultura, número 29, enero de 2008, pág. 72.

${ }^{17}$ Cabrero Enrique y Arellano, David, Los gobiernos municipales a debate. Un análisis de la institución municipal a través de la encuesta del InEGI, 2009, México, Centro de Investigación y Docencia Económica, 2011, p. 97.

${ }^{18}$ Aregional, "Índice de viabilidad financiera municipal (IVFm)", Arinformación. [Consulta: 20 de octubre, 2017]. Disponible en: http://www.arinformacion.com/?target=ivfm

${ }^{19}$ Huntington, Samuel, Political Order in Changing Societies, New Haven and London, Yale University Press, 1968.
} 
como propios de la gobernanza. ${ }^{20}$ Sin embargo, no han tocado fondo los cambios en los cimientos institucionales.

Samuel Huntington rompe con la idea difundida y la hipótesis del gobierno de que la modernización traería simultáneamente progreso y desarrollo económico y político. En su libro El orden político en sociedades en cambio encuentra lo opuesto: la modernización produce caos e inestabilidad si no existen las instituciones necesarias para frenar las ambiciones personales de los políticos y del mercado. La modernización, sostiene Huntington, es un proceso disruptivo. Para los países en desarrollo, fue muy difícil avanzar por la falta de instituciones eficaces y adecuadas para este proceso. Lo mismo está sucediendo en el nivel municipal. No existen las instituciones que permitan insertarse en la globalización, el libre mercado, la competitividad electoral, la emergencia de la sociedad civil y la participación ciudadana, entre otros retos como el tema de la reelección de alcaldes ya presente en la agenda política. ${ }^{21}$

Establece que las instituciones políticas tienen dimensiones morales, tanto como estructurales. Huntington, destaca en su análisis que, si las instituciones son débiles, carecen de capacidad necesaria para contener el exceso de ambiciones personales de los políticos. "Sin instituciones políticas fuertes, la sociedad carece de medios para definir y realizar sus intereses comunes. La capacidad para crear instituciones públicas equivale a lo necesario para crear intereses públicos". ${ }^{22}$

Esto lleva invariablemente al tema de la democracia. Define a la democracia en términos de instituciones políticas como puede ser el gobierno municipal. Huntington destaca tres elementos básicos: a) que los gobernantes emanen de elecciones transparentes y regulares; $b$ ) que la competencia por el poder sea franca y abierta, y c) que el derecho de voto sea casi universal. Por supuesto, en el sistema electoral mexicano se cumple con estas premisas, pero ello no garantiza una calidad democrática basada en representación efectiva, desarrollo social y económico, transparencia y rendición de cuentas.

Se cumple con la democracia procedimental de la cual Schumpeter reconoce debe fincarse en instituciones, no sólo en ideales: "El método democrático como aquel sistema institucional que para llegar a las decisiones políticas, los

\footnotetext{
${ }^{20}$ Aguilar Villanueva, Luis, Gobernanza: El nuevo proceso de gobernar, México, Fúr die Freiheit, 2010.

${ }^{21}$ Huntington, Samuel, Political Order in Changing Societies, New Haven and London, Yale University Press, 1968, p. 129.

22 Huntington, Samuel, Political Order in Changing Societies, New Haven and London, Yale University Press, 1968, p. 1332.
} 
individuos adquieren el poder de decidir por medio de una lucha de competencia por el voto". ${ }^{23}$

Por ello, el propósito principal de este trabajo es establecer una discusión concreta sobre las inconsistencias y limitaciones de la institución municipal, como a continuación se describe, siguiendo las aportaciones del politólogo Guillermo 0'Donnell.

\section{INCONSISTENCIAS DEL GOBIERNO MUNICIPAL}

La institución municipal es una pieza rezagada dentro del Estado mexicano. A pesar de las reformas que ha sufrido el artículo 115 constitucional, sobre el cual se finca el poder local (según Mauricio Merino ${ }^{24}$ y Gámiz) ${ }^{25}$ no se ha logrado garantizar un fuerte gobierno con contrapesos y capaz de garantizar la representación sustantiva.

Podemos decir, en ese sentido, que es preciso que la agencia pueda emerger con las reformas planteadas en los artículos modificados para garantizar la reelección consecutiva en el ámbito municipal. Avanzar en términos de agencia (es decir, promover el poder de los agentes), implica la presunción de capacidades en la toma de decisiones, vinculantes con el bienestar general; tanto en términos de agregación de votos, como del ejercicio de cargos gubernamentales o estatales. ${ }^{26}$

El diagnóstico sobre las necesidades del gobierno local no es nuevo. Isela Orihuela sostiene que el municipio enfrenta nuevas demandas y retos, producto de la disparidad entre los más de 2400 existentes. ${ }^{27}$ Por ello, en varios municipios del país, los gobiernos tratan de ir más allá de sus atribuciones constitucionales para crear nuevas formas de gobierno, de prestación de servicios y de interacción con la sociedad que los acerquen a los requerimientos primordiales de ésta e incluyan nuevos actores locales. Enrique Cabrero ha documentado ampliamente las innovaciones de los municipios, pero el asunto está en que el

\footnotetext{
${ }^{23}$ Schumpeter, Joseph, Theory of Economic Development: An Inquiry About Profits, Capital, Credit, Interest and the Business Cycle, Sao Paulo, Abril Cultural, 1982.

${ }^{24}$ Merino, Mauricio, Gobierno local, poder nacional. La contienda por la formación del Estado Mexicano, México, El Colegio de México, 1998

${ }^{25}$ Gamiz Parral, Máximo, Derecho constitucional y administrativo en las entidades federativas, México, Universidad Nacional Autónoma de México, 2003.

${ }^{26}$ O'Donnell, Guillermo, Democracia, agencia y Estado. Teoría con intención comparativa, Buenos Aires, Prometeo, 2010, p. 40.

${ }^{27}$ Orihuela Jurado, Isela, "Gobiernos locales y municipios", Riguzzi Paolo y Luis Jaime Sobrino (coords.), Historia General ilustrada del Estado de México, México, Biblioteca Mexiquense del Bicentenario, pp. 469-496
} 
municipio mexicano, como institución política, carece de ciertas funciones que limitan su desempeño. ${ }^{28}$

Estrada y Molina proponen un rediseño de la representación política, para promover una representación territorial de los regidores. Es decir, garantizar espacios de circunscripción para su actuar, generando con ello mayor responsabilidad y la capacidad de que los ciudadanos logren incidir en la toma de decisiones, eliminando con ello la discrecionalidad y otros problemas. ${ }^{29}$

Si a ello le sumamos el clientelismo político, nepotismo, paternalismo, etcétera, nos encontramos con que difícilmente existe calidad democrática en los gobiernos locales. Además, el esquema institucional se reproduce del nivel macro al nivel micro, es decir, la estructura a nivel nacional con ausencia de control democrático tiene su correlato en la institución local. Uno de estos frenos a la democracia se encuentra en el sistema electoral que produce y reproduce las estructuras de poder. Las fallas también se extienden al ámbito administrativo, social, político y económico como se describe a continuación.

Existe poca participación política de los ciudadanos en la toma de decisiones, así como en los esquemas institucionales prevalecientes en los municipios. Los ayuntamientos como estructura administrativa no promueven la toma de decisiones consensada o el uso de presupuestos participativos en la mayoría de los gobiernos locales. Esto habla también, de acuerdo con Huntington, de una falta de sistema político tradicional y obsoleto: "El nivel de participación política distingue a los sistemas políticos tradicionales de los modernos. El grado de institucionalización política distingue los sistemas desarrollados de los subdesarrollados". ${ }^{30}$

En el cuadro 1 se enlistan y sintetizan las principales limitaciones institucionales del gobierno local. Partiendo de una visión general, un esquema macro que por supuesto requiere ser enfocado a cada escenario y ejemplo concreto.

\footnotetext{
${ }^{28}$ Cabrero, Enrioue, Innovación en gobiernos locales: un panorama de experiencias municipales en México, México, CIDE - Fundación Ford, 2002.

${ }^{29}$ Estrada Rodriguez, José Luis y Molina Portillo, Cesar, "Hacia la representación efectiva de los regidores: propuesta basada en la teoría del Agente-Principal", Revista Iniciativa, año 9, núm. 33, pp. 33-54.

30 Huntington, Samuel, Political Order in Changing Societies, New Haven and London, Yale University Press, 1968, p. 204.
} 
Cuadro 1. Limitaciones institucionales del municipio

\begin{tabular}{|c|l|}
\hline Ámbito & \multicolumn{1}{|c|}{ Descripción de las limitantes para la calidad democrática } \\
\hline Político & $\begin{array}{l}\text { Centralización en la toma de decisiones al gobierno federal y estatal; línea } \\
\text { difusa entre las atribuciones de los estados y los municipios; intereses } \\
\text { particulares de los alcaldes en conflicto con los intereses sociales. Resulta } \\
\text { insuficiente el periodo de } 3 \text { años para un proyecto vinculado con la reelección } \\
\text { recién aprobada. }\end{array}$ \\
\hline Electoral & $\begin{array}{l}\text { En su mayoría el gobierno local se elige mediante un sistema de listas } \\
\text { cerradas, con cláusula de gobernabilidad o mayoría. Esto impide contrapeso al } \\
\text { Ejecutivo municipal, asimismo, convierte a los regidores en sumisos e } \\
\text { impedidos para promover iniciativas. La deliberación por tanto en el cabildo, } \\
\text { es inexistente. }\end{array}$ \\
\hline Administrativo \\
$\begin{array}{l}\text { Insuficiente capacidad del personal, carencia de profesionalización y servicio } \\
\text { civil de carrera; en su mayoría el marco normativo es pobre y escaso para las } \\
\text { expectativas que tiene la sociedad; incapacidad técnica y tecnológica. El cobro } \\
\text { de los servicios es ineficiente, depende de las transferencias; sin incentivos } \\
\text { para recaudar más por temor al costo político que ello representa. Carece de } \\
\text { autonomía fiscal. }\end{array}$ \\
\hline $\begin{array}{l}\text { En términos de agencia, los municipios carecen de mecanismos para promover } \\
\text { la participación social, existe un fuerte centralismo político, clientelismo, } \\
\text { paternalismo y caciquismo. Los agentes, es decir, los ciudadanos están } \\
\text { excluidos en la toma de decisiones y la participación efectiva. Además existe } \\
\text { una amplia desconfianza hacia los gobiernos locales; producto de la falta de } \\
\text { transparencia y rendición de cuentas. }\end{array}$ \\
\hline
\end{tabular}

Fuente: Elaboración propia

En torno al rubro político, es destacable que ante la inminente reelección de alcaldes que deberá definirse por cada estado, se precisa un área de oportunidad para transformar el caciquismo, el clientelismo y la falta de transparencia. Sin embargo, la reforma política que sustenta la reelección otorga a los partidos políticos nuevamente el control sobre los presidentes municipales. Establece que deberán ser propuestos por sus partidos políticos o en su defecto el partido en alianza. No hay candidaturas libres; seguirán sujetos al partido.

Si bien es un área de oportunidad, la reelección consecutiva en el ámbito municipal es propicia para desarrollar modificaciones en las instituciones y el orden legal que lo controla. Para ello, la reflexión va hacia los mecanismos necesarios para modificar el diseño institucional como vía para la calidad democrática.

\section{Modificaciones Sustanciales para garantizar la agencia}

La democracia está formada por múltiples variables y elementos transversales que constituyen un valor público. Adopta, para tal efecto, un cúmulo histórico 
de derechos, no sólo políticos, sino también civiles, sociales y culturales. Por tanto, una transformación en cualquiera de sus elementos podría reestructurar la relación entre los agentes (ciudadanos) y el Estado, en términos de representación política; la base de la democracia representativa. Un elemento que debe fomentar el rediseño de la representación a nivel municipal sine qua non de la democracia es la deliberación.

Eso es lo que requiere una modificación sustancial, porque el mecanismo institucional a partir del cual se da la distribución del poder está centralizado y controlado por el presidente municipal. Desde su formación, no se precisa si el "municipio libre" es un sistema de corte netamente parlamentario, por ser colegiado a través del cabildo, o presidencial, porque predomina siempre en su seno la figura del Ejecutivo municipal, quien goza del control de la mayoría. El diseño institucional electoral no genera contrapesos y, por supuesto, eso impide la deliberación plena, así como la apertura democrática para que los ciudadanos puedan subir sus demandas.

Desde 1983, en los municipios se cuenta con la representación proporcionan en los cabildos, pero existe gran diversidad de métodos y criterios para integrar la representación política de sus autoridades. La constante es que los miembros del cabildo no son contrapeso al alcalde. Existen al menos tres distintas formas de integrar a los ayuntamientos luego de la elección: a) Criterio poblacional, $b$ ) Criterio diferencial, que ajusta la representación proporcional y, c) Criterio electoral, basado en el número de votantes. Sólo dos estados, Aguascalientes y Tabasco, tienen métodos combinados para la integración de los ayuntamientos. El sistema diferencial es usado por doce estados, poblacional en quince, y electoral en dos (Coahuila y Nayarit). ${ }^{31}$

Las instituciones determinan la democracia en las entidades estatales. Francis Fukuyama establece que la participación política incide en la calidad democrática porque construye puentes de vigilancia y control hacia los políticos, pero también promueve el desarrollo de una administración eficiente. Empero, no es suficiente, también debe garantirse la gobernabilidad, un país con equilibrio social e instituciones que respalden los derechos humanos. ${ }^{32}$

Por tanto, la discusión está en la calidad del gobierno, como una vía para la calidad democrática. En la medida en que los procesos institucionales se garantizan para los agentes, se logra el involucramiento y participación ciudadana y se contribuye, por tanto, al desarrollo. Para ello, es preciso contar con un sistema

\footnotetext{
${ }^{31}$ HuRtAdo, Javier, Representación política y municipio en México. El caso de la capital de Durango, Serie Comentarios a las Sentencias del tribunal electoral, México, Tribunal Electoral del Poder Judicial de la Federación, 2012.

${ }^{32}$ FukuYama, Francis, "Democracy and the quality of the state", Journal of Democracy, vol. 24, núm. 4, pp. 5-16
} 
legal que sancione y respalde los derechos y libertades ciudadanas; por otra parte, se debe contar con un subconjunto de burocracias, consistente en la efectividad de los derechos y libertades. John Rawls encamina sus reflexiones hacia el mismo sentido. Es preciso que las instituciones garanticen una distribución equitativa de cooperación social, con un componente moral y ético en el debate jurídico para disminuir las desigualdades sociales y naturales. ${ }^{33}$ Con ello, se entiende, se puede mejorar mecanismos para elaborar elevar demandas ante el cabildo e incidir en la toma de decisiones, por la vía del debate y la deliberación.

Por lo tanto, la vía de transformación y modificación de las pautas democráticas está transversalmente condicionada por el sistema legal. Por ello, las modificaciones en el artículo 115 constitucional son determinantes para garantizar el desarrollo democrático del gobierno local y, de manera concomitante, su efectividad gubernamental de respuesta a los ciudadanos. El sistema legal, insiste 0’Donnell, es lo que promueve la atención y desarrollo de los agentes sociales. ${ }^{34}$

Rawls prioriza como condición de la democracia e igualdad las libertades cívicas de pensamiento, conciencia y propiedad privada; y en segundo lugar pone las libertades políticas, subordinando las cívicas que confluyen con el respeto a los derechos humanos y la condición social. Aborda la disputa y la resuelve en favor de las libertades políticas. Interpreta la libertad y la igualdad como postulados convergentes que congenian con la noción de persona moral, la cual articula la concepción de una sociedad bien ordenada a través de la posición original, donde las partes son definidas como agentes de construcción racionales, autónomos e iguales.

Los regidores, integrantes del cabildo en los gobiernos locales, aunque no legislen (porque no tienen esas atribuciones), son los representantes del pueblo dentro de la estructura de Estado. Reciben un mandato que libera a los propios ciudadanos de participar activamente en la consecución de sus demandas. Empero, en ocasiones se produce un doble proceso de delegación, porque a la vez que los ciudadanos delegan a sus representantes, éstos, a través del otorgamiento de facultades especiales (por ejemplo, los decretos de urgencia), delegan la función legislativa y de control en el poder ejecutivo municipal. Esto genera una democracia delegativa, término acuñado por 0’Donnell ${ }^{35}$ y retomado por

\footnotetext{
${ }^{33}$ Rawls, John, Teoría de la justicia, México, Fondo de Cultura Económica, 1997.

${ }^{34}$ O'Donnell, Guillermo, Democracia, agencia y Estado. Teoría con intención comparativa, Buenos Aires, Prometeo, 2010, p. 17.

${ }^{35}$ O'Donnell, Guillermo, "Delegative Democracy", Journal of Democracy, vol. 5, núm. 1, pp. 55-69.
} 
David Held.$^{36}$ Los agentes, en ese sentido, son quienes se encuentran facultados en el pacto y cesión poderes.

Una analogía de esta democracia delegativa puede utilizarse para analizar el desempeño de los gobiernos municipales en México: si bien se trata de un gobierno colegiado, una vez electo, el presidente municipal actúa como si se tratara de un gobierno unipersonal.

0’Donnell acuñó el concepto democracia delegativa para analizar los gobiernos de Menen en Argentina, Collor en Brasil y Alberto Fujimori en la década de los noventa. Las democracias delegativas surgieron en América Latina producto de elecciones libres, derivados de una crisis política que logró posicionarlos de inmediato. Tenían características que los definían: creían tener el derecho de actuar y decidir sobre lo mejor para el país; pero desdeñaban el control institucional. Afirmaban que era un obstáculo para enfrentar la crisis; por tanto, estos líderes subordinaron, suprimieron y cooptaron estas instituciones. El sistema electoral, el diseño institucional y la tradición de centralismo político han puesto a los municipios en manos de presidentes municipales con poderes de facto extraordinarios que prescinden de sus cabildos para gobernar.

Por ello, la deliberación plena es uno de los mecanismos que puede corregir la desviación representativa que vive el gobierno municipal, además de la reelección consecutiva que será posible a partir de 2015. La deliberación, como un mecanismo de agregación de intereses y búsqueda de consensos, es una salida a la crisis de representación. En el gobierno municipal, la falta de un proceso deliberativo cuestiona la legitimidad de los representantes.

Como sostiene David Held, la fuente de legitimidad de las acciones emprendidas por el gobierno no está en la voluntad predeterminada de los individuos, producto de la elección; sino en su proceso de formación a partir de la deliberación. El gobierno municipal podrá contar con una mayor legitimidad política en la medida en que su gestión se funde en procesos deliberativos, se promueva, de manera institucional, la construcción de acuerdos y se deje atrás el esquema de la democracia delegativa. ${ }^{37}$

Avanzar en la calidad de la democracia requiere transformar las reglas del juego, y garantizar mecanismos de control y pautas de deliberación de los asuntos públicos. La democracia representativa debe llevar a una rendición de cuentas institucionalizada:

\footnotetext{
${ }^{36}$ Held, David, Modelos de democracia, España, Alianza, p. 39.

${ }^{37}$ O'Donell, Guillermo, "Horizontal Accountability: The Legal Institutionalization of Mistrust", en Scott Mainwaring and Christoper Welna, Democratic Accountability in Latin America, Oxford, Oxford Scholarship, 2003.
} 
En las democracias institucionalizadas, la rendición de cuentas funciona no sólo de manera vertical, de modo que los funcionarios elegidos sean responsables frente al electorado; sino también en forma horizontal; a través de una red de poderes relativamente autónomos, es decir a otras instituciones que pueden cuestionar, y finalmente castigar, las formas incorrectas de liberar de responsabilidades a un funcionario determinado. La representación y la rendición de cuentas llevan en sí la dimensión republicana de la democracia; la existencia y la observancia de una meticulosa entre los intereses públicos y privados de quienes ocupan cargos públicos. ${ }^{38}$

Por ello, Held considera que la deliberación es el mecanismo que debe privilegiarse como vía para garantizar la calidad de la democracia:

La deliberación pública puede mostrar cómo la formación de determinadas preferencias puede estar relacionada con intereses sectoriales, garantizando un objetivo ideológico. En tal caso, la deliberación puede exponer la parcialidad y unilateralidad de algunos puntos de vista que no representan los intereses de la mayoría. ${ }^{39}$

En la discusión sobre el comportamiento de los políticos y su actuación racional ente los dilemas ante los cuales se hallan, Adam Przeworski señala que los políticos pueden encontrar incentivos para desviarse del mandato, pero lo hacen pensando en que están actuando de acuerdo con el interés de los ciudadanos. Los agentes, en este caso, si no ejercen acciones de contrapeso, desvían la función de la representación. ${ }^{40}$ En contraparte, sucede que los ciudadanos o agentes, una vez que han elegido a sus representantes, no cuentan con mecanismos institucionales para obligarlos a mantener sus promesas. Los electores o agentes sólo pueden sancionar las desviaciones del mandato después de que hayan experimentado sus efectos, lo cual no sirve de mucho ni corrige los problemas derivados de la mala actuación de los políticos en el momento.

\footnotetext{
${ }^{38}$ O'Donnell, Guillermo, "Delegative Democracy", Journal of Democracy, vol. 5, núm. 1, p. 14.

${ }^{39}$ Held, David, Modelos de democracia, España, Alianza, 2007, p. 34.

${ }^{40}$ Przeworsky, AdAm, "Democracia y representación", Revista del CLAD, reforma y desarrollo, núm. 10.
} 
Asimismo, Michel Celi, ${ }^{41}$ Víctor Hugo Martínez ${ }^{42}$ y Alcántara ${ }^{43}$ advierten que esta pérdida de representatividad, credibilidad y legitimidad de los partidos políticos está produciendo la fragilización de las estructuras del Estado, ante la incapacidad de solucionar los graves problemas económicos y sociales. La globalización económica es uno de los factores que incide de manera directa en el malestar democrático. Los ciudadanos no encuentran solución a sus demandas, a sus necesidades de empleo y bienestar social.

Hasta ahora, en la discusión académica se ha planteado el tema del mandato en el contexto histórico y en el desarrollo de este término a través de su evolución. Ciertamente, el mandato imperativo es imposible de sostenerse en las actuales democracias, pero se han generado mecanismos de control sobre los representantes que permitan evitar el abuso de los políticos que detentan algún espacio de poder (como diputados, senadores y, en nuestro trabajo, los regidores de un ayuntamiento).

La democracia no sólo está vinculada con el ejercicio de los derechos ciudadanos, sino también con generar espacios para la participación abierta y la crítica de los asuntos de interés general. Para Habermas, la representación política se forma a partir de la voluntad general del pueblo, ese es el esquema ideal sobre el cual se sostiene este principio democrático, de tal forma que la génesis de la voluntad política se encuentra en las tramas asociativas multiformes, como partidos políticos, sindicatos, iglesias, foros de discusión, asociaciones de vecinos, organizaciones no gubernamentales y otros ámbitos no institucionalizados. ${ }^{44}$

En el espacio local, es notorio el desarrollo de organizaciones, grupos de interés, grupos políticos, asociaciones no gubernamentales y asociaciones de vecinos de las distintas colonias. Así, el espacio público del gobierno municipal es uno de los más ricos de las distintas esferas de gobierno; un entramado de redes con distintas necesidades que están buscando en todo momento incidir en la política municipal y en la toma de decisiones.

La deliberación surge como un espacio de corrección a la falta de representación efectiva, siempre y cuando se ejerza en el ámbito local. Se busca hacer que este mecanismo garantice la democracia y, por supuesto, la representación

\footnotetext{
${ }^{41}$ Cel Vargas, Michel, "Los partidos políticos y la crisis institucional en el marco de la globalización económica", IV Congreso Europeo CEISAL de Latinoamericanistas. [Consulta: 18 de diciembre, 2009]. Disponible en: http://cms.cecal. net/sites/default/files/ceisal_cecal_celi_vegas_bratislava_2004.pdf

${ }^{42}$ Martinez Gonzalez, Victor Hugo, "Partidos políticos y calidad de la democracia. Notas para un 'nuevo debate'", Apuntes electorales, nueva época, año 8, núm. 35, pp. 47-67.

${ }^{43}$ Alcántara Sáenz, Manuel, "Calidad de la democracia y retos de la política en América Latina", en Vivero Igor, Democracia y reformas políticas en México y América Latina, México, Miguel Ángel Porrúa - IEEM - IAPEM - UAEM, 2010.

${ }^{44}$ Habermas, Jürgen, La inclusión del otro. Estudios de teoría política, España, Paidós, 1999, p. 67.
} 
de intereses generales, incluir las peticiones y propuestas ciudadanas para llevarlas a la toma de decisiones en el cabildo. Habermas reconoce la dificultad de actuar de manera vinculante desde el poder y atender las demandas ciudadanas. Establece que es en estas redes de organizaciones y grupos donde se formulan las necesidades y se privilegia la agenda. ${ }^{45}$ Asimismo, se elaboran las propuestas políticas concretas que desean dar a conocer a sus representantes; en el caso del gobierno municipal, a sus regidores y al presidente municipal

Un mecanismo derivado del mandato es la deliberación. Junto con este término surge la democracia deliberativa. Desde esta perspectiva, los representantes deben privilegiar la comunicación, el diálogo y que se imponga en toda decisión la discusión sobre los argumentos y no los votos. Esto significa que, en un cabildo, para garantizar una deliberación y una efectiva representación de los intereses de los votantes, debe existir una amplia discusión sobre los beneficios y perjuicios de cada acción del gobierno municipal. Con ello se garantiza que se tomen en cuenta las opiniones de los ciudadanos como agentes democráticos, representados en la deliberación que se lleva a cabo en el cabildo. "Simplemente no hay democracia donde no hay deliberación, sea en el seno de la sociedad civil o en el seno del Estado". ${ }^{46}$

Este planeamiento sobre la deliberación como mecanismo para garantizar que los representantes sean responsivos o responsables con sus electores puede considerarse como un tipo ideal en el estudio de la democracia. Jon Elster señalan al menos cuatro maneras mediante las cuales puede incidir la deliberación en torno a la calidad en la toma de decisiones: a) Lograr que los resultados de las decisiones sean superiores en la clasificación de Pareto al permitir mayores soluciones, b) Lograr decisiones más equitativas en términos de justicia distributiva proporcionando mayor protección a las partes más débiles, c) Conducir a un consenso más amplio sobre cualquier decisión, $d$ ) Generar decisiones más legítimas (incluso para la minoría). ${ }^{47}$

El planteamiento que se esgrime en esta postura está vinculado de manera directa con la legitimidad en la toma de decisiones. La discusión de los temas antes de votar otorga a los representantes la posibilidad de sostener con argumentos y con posturas ideológicas el porqué de su voto. Se trata de justificar el voto que emiten en el pleno o en el cabildo a partir de su discusión. Esto convence a los electores o agentes de seguir votando por los representantes que

\footnotetext{
${ }^{45}$ Habermas, Jürgen, La inclusión del otro. Estudios de teoría política, España, Paidós, 1999, p. 80.

${ }^{46}$ Fernández Santillán, José, "Ideas sobre la esfera pública", Mariñez Navarro Freddy, Ciudadanos, decisiones públicas y calidad de la democracia, México, Limusa - Noriega, 2007, pp. 171-178.

${ }^{47}$ ELSTER, Jon, La democracia deliberativa, Barcelona, Gedisa, 2001.
} 
se apegan a sus promesas de campaña y que llevan la agenda ciudadana a la discusión; aunque no siempre ganen, por supuesto.

En este punto, la información juega un papel importante, porque en la deliberación los datos con respecto al tema garantizan una sólida argumentación. Empero, si los actores no cuentan con la misma información no se podrá garantizar un proceso de deliberación genuino, porque se corre el riesgo de que quienes cuenten con toda la información convenzan a los otros actores o los engañen utilizando el criterio ideológico antes que la razón.

Sin embargo, aunque la representación plena mediante la deliberación es un mecanismo efectivo para la agregación de intereses, también tiene fallas y riesgos. Bruce Guilley advierte que existen intereses económicos, políticos y culturales capaces de influir y manipular las propuestas, porque la democracia también tiene detractores y se cuestiona su factibilidad..$^{48}$ Una forma de control es tergiversando la información; otra, limitando la información; y una más, ocultando la información. En ese sentido, la representación plena que tiene como mecanismo la deliberación de los asuntos públicos depende de la información. Los legisladores o, en el caso de los gobiernos locales, los regidores deberán contar con la mayor información disponible para hallar la mejor opción.

En el caso de los regidores de un ayuntamiento, que es el caso que nos ocupa, ocurre frecuentemente que no todos los regidores cuentan con la misma información antes del cabildo. Usualmente, los regidores de mayoría o pertenecientes a la planilla del presidente pueden tener mayor información, mientras que los regidores de oposición carecen de ella; o en todo caso, el único que cuenta con información plena es el presidente municipal y los regidores de mayoría actúan disciplinadamente con aquél. Así, para caminar hacia la reelección consecutiva se requiere, al menos, promover un esquema de igualdad en torno al proceso deliberativo.

Por esa razón, ante el desconocimiento del tema, es imposible garantizar que los regidores de un ayuntamiento deliberen para llegar a mejores propuestas, acciones o políticas públicas de beneficio colectivo, consensado y democrático. Los representantes, o los regidores en el caso del gobierno local, requieren contar con igualdad de condiciones al recibir la información para deliberar en torno a ella. Buscar la imparcialidad es una de las premisas que salvaguarda la deliberación.

En ese sentido, Joseph Colomer establece que en la medida en que las decisiones que afectan una región, provincia o municipio sean tomadas por el

\footnotetext{
${ }^{48}$ Guilley, Bruce, "Is democracy posible?", Journal of Democracy, vol. 20, núm. 1, p. 116.
} 
mayor número de personas en consenso, se garantizará la legitimidad del gobierno, en la medida en que se agregan preferencias individuales. ${ }^{49} \mathrm{El}$ problema, dice Colomer, es que los arreglos institucionales están basados en un centralismo en la toma de decisiones y la imposición, muchas veces en contra de la mayoría. De tal suerte, una forma de corrección que podría instrumentarse en un cabildo municipal sería garantizando la deliberación y el espacio público de la discusión a partir de otorgarles la palabra y la información.

Empero, el camino de la representación nos lleva de inmediato al sistema institucional bajo el cual se construye dicha representación. Tal como sostiene Gargarella:

El sistema político parece tener problemas para alcanzar decisiones imparciales y -probablemente a causa de eso-, experimenta dificultad en ganarse el respeto del público. Conjeturo que tales problemas tienen por lo menos una causa importante: el sistema político (organizado de modo como lo está) no se halla en condiciones de asegurar la plena representación de la sociedad..$^{50}$

La fórmula para garantizar la imparcialidad está basada en la "representación plena" que postula Gargarella, la cual significa que los representantes tomen las peticiones y los asuntos como si fueran suyos. Asimismo, centrando el análisis en el cabildo, el órgano deliberativo del gobierno local, la comunicación es un elemento que se debe privilegiar en la toma de decisiones, porque los grupos políticos pueden impulsar alianzas y negociar, partir de la información propuesta y no sólo turnar los dictámenes a votación. Bajo el esquema institucional que rige a los ayuntamientos en nuestro país, el sistema de planilla cerrada y bloqueada garantiza que, si se vota un asunto que promueve el presidente, los regidores de su planilla votarán a su favor. Cuando el sistema institucional en la asignación de regidores garantiza la mayoría de la representación edilicia, impide el contrapeso legítimo de la oposición. No hay deliberación, sólo mayoriteo en las votaciones.

\section{Puntos concluyentes}

Para poder garantizar en principio la democracia y el desarrollo de pautas institucionales para la construcción de agencia en el gobierno municipal, es preciso

\footnotetext{
${ }^{49}$ Colomer, Joseph, Las instituciones y el federalismo, documento de trabajo, México, Flacso, 1999.

${ }^{50}$ Gargarella, Roberto, Crisis de la representación política, México, Fontamara, 2002, p. 93.
} 
que las instituciones lo promuevan y favorezcan. Esto significa transformar el sistema institucional electoral local en el nivel micro y el sistema político en el nivel macro.

Actualmente, como se describió, los municipios de todo el país enfrentan grandes retos para avanzar en un nuevo orden de gobierno. Uno de ellos, fundamental, es promover la transformación institucional para modificar la relación entre gobernantes y gobernados, por la vía de la agencia. 0’Donnell sostiene que sólo con modificaciones de fondo en la estructura institucional se podrá incidir en el mejoramiento de la democracia.

0’Donnell establece la apremiante necesidad de construir control sobre los políticos. La reelección es uno de los mecanismos, pero también será necesario generar una red de agencias (fiscalías, contralorías, organizaciones ciudadanas) que permitan detener el autoritarismo y evitar la dictadura de los gobiernos. Las sugerencias que realiza también podrían aplicarse en México: a) Que las instituciones de control hacia los políticos estén en manos de los partidos de oposición; b) Profesionalizar el poder judicial a fin de garantizar la imparcialidad en la justicia; c) Promover la independencia de las instituciones, del poder Ejecutivo, para evitar el centralismo y el paternalismo; d) Construir reglas, leyes y normas a favor de los ciudadanos.

Por lo tanto, la hipótesis inicial sobre la urgencia de establecer cambios y modificaciones en la representación municipal se sostiene, sobre todo a partir de contemplar el paradigma de la democratización basados en 0'Donnell. Si bien la reelección es una política compensatoria, requiere de otros mecanismos para garantizar su fiel aplicación y acceso a la calidad democrática.

Existen otros fenómenos socio-culturales que inciden en la representación política; sin embargo, también deben atenderse con la reforma que otorgará la posibilidad de reelección consecutiva en México, la globalización, la apertura de mercados y la competencia, así como el crecimiento de las ciudades implica la exigencia de modificaciones en el esquema institucional. Los ciudadanos como agentes no sólo tienen beneficios, sino también responsabilidades.

Por una parte, es necesario que los ayuntamientos logren recaudar más, urgen reformas de liberación e incentivos para la recaudación fiscal. Sin fuentes de financiamiento para obtener ingresos propios, seguirán bajo el control central. Ante las diferencias entre los municipios, en 2009, 29\% son urbanos y 74\% son rurales. Los cambios para lograr su transformación deberán de ser paulatinos y deben atender a las enormes diferencias.

Empero, en el plano político, la reelección consecutiva plantea el rescate de la representación, porque hará emerger liderazgos y transformará las vías 
de ascenso al poder. La deliberación es otro aspecto que se debe fortalecer. Las campañas políticas serán distintas a partir de la reforma político-electoral, y por ello es preciso vigorizar a los ciudadanos, empoderarlos para garantizar su papel dentro del régimen democrático. Contar con un mejor gobierno depende en el ámbito micro de los ciudadanos, y en el macro, de las instituciones. Sobre estos puntos focales deberá centrarse la discusión de las leyes secundarias en materia de reelección.

Asimismo, es preciso avanzar en el rediseño de la representación política municipal. Con la reelección aprobada en el congreso, todavía no se han delineado los mecanismos a través de los cuales se dará este cambio. Por lo tanto, es una ambiciosa agenda de trabajo que se pude impulsar para transformar el entramado institucional del municipio. La representación territorial, como un mecanismo que permita conocer quiénes son los representantes de cada localidad, es una vía para construcción de ciudadanía y de empoderamiento de los agentes. Los regidores podrían, bajo este mecanismo, distribuir sus tareas de gestión en territorios específicos. Actualmente los regidores cuentan con comisiones, pero la representación se diluye en todo el cuerpo edilicio, por una parte; por otra, no están definidas sus funciones.

De igual forma, eliminar el centralismo político es una de las primeras tareas; así como el clientelismo y el paternalismo, es característico de la cultura política de los súbditos, no de los ciudadanos. Esta posición, afortunadamente, está cambiando. Junto con ello, la emergencia de nuevos actores, agentes y formas de participación social parecen ser los elementos que detonarán el cambio dentro del gobierno local y sobre lo cual es preciso discutir propuestas legislativas y abrir el panorama al nuevo municipio mexicano.

\section{REFERENCIAS BIBLIOGRÁFICAS}

Aguilar Villanueva, Luis, Gobernanza: El nuevo proceso de gobernar. FÚR DIE FREIHEIT, México, 2010.

Alcántara SÁenz, Manuel, "Calidad de la democracia y retos de la politica en América Latina”, en Vivero Igor, Democracia y reformas politicas en México y América Latina, México, Miguel Ángel Porrúa - ieem - iapem - uaem, 2010. Aregional, "Índice de vaibilidad financiera municipal (IVFM)", Arinformación. [Consulta: 20 de octubre, 2017]. Disponible en: http://www.arinformacion. COM/?TARGET=IVFM

Arellano, David, Cabrero Mendoza, Enrique, Montiel Cuayatlayol María José y Aguilar Márquez, Israel, “Gobierno y administración pública municipal: un 
panorama de la fragilidad institucionalizada”, en Enrique Cabrero y David Arellano, Los gobiernos municipales a debate. Un análisis de la institución municipal a través de la encuesta del INEGI, 2009, México, CIDE.

Cabrero Enrique Y Arellano, David (COORDS.), Los gobiernos municipales a debate. Un análisis de la institución municipal a través de la Encuesta de INEGI, 2009, Centro de Investigación y Docencia Económica, México, 2011.

CABRero, EnRIQUe, Innovación en gobiernos locales: un panorama de experiencias municipales en México, CIDE, Fundación Ford, México, 2002.

Castellanos Cereceda, ROBERTO, La reforma político-electoral de 2014. Diagnóstico, primeros resultados y principales desafios, Instituto Belisario Domínguez, México, 2016.

Celi Bargas, Michel, "Los partidos políticos y la crisis institucional en el marco de la globalización económica”, IV Congreso Europeo CEISAL de Latinoamericanistas. [Consulta: 18 de diciembre, 2009]. Disponible en: http: //cms.cecal. net/sites/default/files/ceisal_cecal_celi_vegas_bratislava_2004.pdf

Celorio JuÁrez Mariana, “La Reforma Político-Electoral de 2014: avances, Retrocesos y vacíos”, El Cotidiano, núm. 190, marzo-abril, 2015, pp. 109-117.

Colomer, Joseph, "Democracy in Latin America: Minimalist in Concept and in Achievement”. Latin American Research Review. 2017; 52(3), pp. 505-512.

DAHL, Robert. La poliarquía. Participación y oposición, editorial Tecnos, Madrid, 1989.

Colomer, Joseph, Las instituciones y el federalismo, documento de trabajo, México, Flacso, 1999.

Elster, Jon, La democracia deliberativa, Barcelona, Gedisa, 2001.

Estrada Rodríguez JosÉ LuIs y CESAR Molina Portillo, "Hacia la representación efectiva de los regidores: propuesta basada en la teoría del Agente-Principal”, Revista Iniciativa, año 9, número 33, enero-junio de 2008, pp. 33-54.

Fama, F. Eugene, "Agency Problems and the Theory of the Firm", The Journal of Political Economy, Vol. 88, No. 2 (Apr., 1980), pp. 288-307

FERnÁNDEZ SANTILLÁn, José, "Ideas sobre la esfera pública”, MARIÑEZ NAVARRO FREDDY, Ciudadanos, decisiones públicas y calidad de la democracia, México, Limusa - Noriega, 2007, pp. 171-178.

FunuYAma, Francis, "Democracy and the quality of the state" Journal of Democracy, Volume 24, Number 4, October 2013, pp. 5-16

Gamiz Parral, Máximo, Derecho constitucional y administrativo en las entidades federativas, México, Universidad Nacional Autónoma de México, 2003.

Gargarella, Roberto, Crisis de la representación politica, México, Fontamara, 2002, p. 93.

Guilley, BRuce, Is democracy posible? Journal of Democracy, January 2009, Volume 20, Number 1, págs. 113-127.

Habermas, Jürgen, La inclusión del otro. Estudios de teoría politica, España, Paidós, 1999, p. 67. 
Hambleton, Robin, Sanvitch Hank V., y Stewart Murray, "Globalism and local democracy”, en HAMBLETON (2003). Globalism and local democracy. Challenge and change in Europe and North America, Palgrave Macmillan, New York, 2003.

Held, DAVID, Modelos de democracia, España, Alianza, 2001

Huntington, Samuel, Political Order in Changing Societies, New Haven and London, Yale University Press, 1968.

Hurtado, Javier, Representación politica y municipio en México. El caso de la capital de Durango, Serie Comentarios a las Sentencias del tribunal electoral, vertiente salas regionales, número 11. Tribunal electoral del Poder Judicial de la Federación, México, 2012.

Martínez González, Víctor Hugo, "Partidos políticos y calidad de la democracia. Notas para un "nuevo debate”. Apuntes electorales, nueva época, año 8, núm. 35, pp. 47-67.

Merino, Mauricio, Gobierno local, poder nacional. La contienda por la formación del Estado Mexicano, México, El Colegio de México, 1998.

Merino, Mauricio, "Nuevo federalismo, nuevos conflictos”, Soledad Loaeza y JEANFRANÇOIS PRUD'HOMME, coordinadores. Los grandes problemas de México, XIV. Instituciones y procesos politicos, El Colegio de México, 2010.

Millán Valenzuela, Henio y Natal Martínez, Alejandro, la rendición de cuentas a la luz de la teoría agente-principal: un análisis de la democracia en México, México, El Colegio Mexiquense, 2006

O’ Donell, Guillermo, Democracia, agencia y Estado. Teoría con intención comparativa. Buenos Aires: Prometeo, 2010

0 'Donell, Guillermo, Horizontal Accountability: The Legal Institutionalization of Mistrust, Scott Mainwaring and Christoper Welna, Democratic Accountability in Latin America, Oxford Scholarship, New York, USA, 2003.

0'Donell, Guilllermo, “Delegative Democracy”, en Journal of Democracy, Vol. 5, $N^{\circ} 1,1994$, págs. 55-69.

Orihuela JuRAdo, Isela, “Gobiernos locales y municipios”, Riguzzi Paolo y Luis Jaime Sobrino (coords.), Historia General Ilustrada del Estado de México, México, Biblioteca Mexiquense del Bicentenario, 2011, pp. 469-496.

PÉREz, DurÁn, Ixchel, "Efectos del diseño electoral municipal en la formación de poder”, Gestión y política pública, Centro de Investigación y Docencia Económicas (CIDE), volumen XVII, número 2, III semestre de 2008, pp. 381-423

Peters, Guy, El nuevo institucionalismo, teoría institucional en Ciencia Politica, Barcelona, Gedisa, 2003.

PRZEWORSKY, AdAM, “Democracia y representación”, Revista del CLAD, reforma y desarrollo, núm, 10, 1998.

Ramos José María E Ismael Aguilar Barajas, La gestión del desarrollo local en México: problemas y agenda, México, El Colegio de la Frontera Norte/ Miguel Ángel Porrúa, 2009. 
Rawls, John, Teoría de la justicia, México, Fondo de Cultura Económica, 1997.

Rivera Urrutia, Eugenio, "Teorías de la regulación en la perspectiva de las políticas públicas", Revista Gestión y política pública, vol. 13, núm. 2, p. 309.

Rodríguez, Wallenius, CARlos, "La agenda ciudadana municipalista y la reforma del Estado", Política y Cultura, número 29, enero de 2008, pág. 72

Sosa López, José De Jesús, "Gobiernos locales y desarrollo territorial en México", Frontera Norte, vol. 24, núm. 47, enero-junio de 2012.

Schumpeter, Joseph A., Theory of Economic Development: An Inquiry About Profits, Capital, Credit, Interest and the Business Cycle. Sao Paulo: Abril Cultural, 1982. 